\title{
Efficacy and safety of low-dose topical tacrolimus in vernal keratoconjunctivitis
}

\author{
This article was published in the following Dove Press journal: \\ Clinical Ophthalmology \\ 7 April 2016 \\ Number of times this article has been viewed
}

\author{
Samir S Shoughy' \\ Mahmoud O Jaroudi' \\ Khalid F Tabbara ${ }^{1-3}$ \\ 'The Eye Center and The Eye \\ Foundation for Research in \\ Ophthalmology, ${ }^{2}$ Department of \\ Ophthalmology, College of Medicine, \\ King Saud University, Riyadh, Saudi \\ Arabia; ${ }^{3}$ Wilmer Ophthalmological \\ Institute of the Johns Hopkins \\ University School of Medicine, \\ Baltimore, MD, USA
}

Objective: The objective of this study was to evaluate the efficacy and safety of topical low-dose tacrolimus $(0.01 \%)$ solution in patients with vernal keratoconjunctivitis (VKC).

Patients and methods: A total of 62 consecutive patients with VKC refractory to conventional treatment were included retrospectively. Tacrolimus $0.01 \%$ ophthalmic solution was administered to patients twice daily after discontinuation of all previous topical medications. The duration of treatment ranged from 1 month to 29 months. The clinical symptoms of itching, redness, foreign body sensation, and discharge and the clinical signs of conjunctival hyperemia, conjunctival papillary hypertrophy, limbal infiltration, Trantas dots, and superficial punctate keratopathy were graded as 0 (normal), $1+$ (mild), 2+ (moderate), or 3+ (severe). Assessment was carried out before initiation of therapy and on the last visit after treatment.

Results: There were 62 patients with VKC comprising 49 male and 13 female patients. The median age was 12 years (range: 5-47 years). The mean visual acuity improved from 20/30 to $20 / 25$ following treatment. There was statistically significant improvement in symptoms of itching $(P<0.001)$, redness $(P<0.001)$, foreign body sensation $(P<0.001)$, and discharge $(P<0.001)$. Statistically significant improvement was also observed in clinical signs of conjunctival hyperemia $(P<0.001)$, limbal infiltration $(P<0.001)$, Trantas dots $(P<0.001)$, superficial punctate keratopathy $(P<0.001)$, and conjunctival papillary hypertrophy $(P<0.001)$. The solution form of tacrolimus was well tolerated. None of the patients developed elevation of intraocular pressure, cataract, or infectious keratitis.

Conclusion: Low-dose topical tacrolimus $0.01 \%$ solution is effective and safe in the management of patients with refractory VKC.

Keywords: topical, solution, tacrolimus, vernal keratoconjunctivitis

\section{Introduction}

Vernal keratoconjunctivitis (VKC) is a chronic bilateral allergic inflammation of the ocular surface, involving the palpebral and/or bulbar conjunctiva. VKC is a potentially blinding disease. Varying prevalence has been reported in different ethnic groups. Young males in dry and hot climates are primarily affected. It is more common in temperate zones of the Mediterranean region, Central and West Africa, the Indian subcontinent, and Central and South America. ${ }^{1}$ Patients with VKC present with itching, redness, photophobia, ocular discomfort, foreign body sensation, and lacrimation, resulting in visual disturbances and loss of school days. VKC has traditionally been considered as an immunoglobulin E (IgE)-mediated disease (type I hypersensitivity). This was supported by accumulation of conjunctival $\mathrm{T}$ helper cells promoting IgE synthesis. ${ }^{2}$ Recent findings implicate a more complex pathogenesis with particular involvement of T helper 2 cells. ${ }^{3}$ Currently available drugs to treat VKC include antihistamines, mast-cell stabilizers, corticosteroids, and immunomodulators. VKC requires
The Eye Center and The Eye Foundation for Research in Ophthalmology, PO Box 55307, Riyadh II534, Saudi Arabia

Tel +966 I I464 96I4

Fax +966 I 14629675

Email samir.shawki@hotmail.com (c) (1) (-) 2016 Shoughy et al. This work is published and licensed by Dove Medical Press Limited. The full terms of this license are available at https://www.dovepress.com/terms.php cC) and incorporate the Creative Commons Attribution - Non Commercial (unported, v3.0) License (http://creativecommons.org/licenses/by-nc/3.0/). By accessing the work you hereby accept the Terms. Non-commercial uses of the work are permitted without any further permission from Dove Medical Press Limited, provided the work is properly attributed. For permission for commercial use of this work, please see paragraphs 4.2 and 5 of our Terms (https://www.dovepress.com/terms.php).
for 
long-term treatment in many cases. Topical steroids are the mainstay of treatment for moderate to severe forms of VKC. Steroids, however, cannot be administered for a long period. Injudicious and prolonged use of topical steroids may lead to glaucoma, cataract, and secondary infections. The risk of steroid-induced ocular complications in VKC is particularly high in children who are the most commonly affected agegroup. ${ }^{4}$

Recently, immunomodulatory agents have been used to avoid steroid-related complications. Tacrolimus has an immunomodulatory and anti-inflammatory activity. Tacrolimus suppresses Th2 lymphocyte activation, T helper cellmediated B-cell proliferation, and formation of cytokines. ${ }^{5}$ Several studies were carried out to assess the success of tacrolimus suspension for treatment of patients with VKC. Most of these studies evaluated the usefulness of relatively high concentration of topical tacrolimus (topical tacrolimus $0.1 \%$ ). ${ }^{6-10}$ The use of high-dose topical tacrolimus in a suspension form was associated with frequent burning sensation and irritation. The purpose of this study was to assess the efficacy and safety of low concentration of topical tacrolimus $(0.01 \%)$ in the form of solution in patients with refractory $\mathrm{VKC}$.

\section{Patients and methods}

The protocol was approved by the institutional review board of The Eye Center and The Eye Foundation for Research in Ophthalmology. The study was adherent to the tenets of the Declaration of Helsinki. Patient consent was obtained. We retrospectively reviewed the medical records of 62 consecutive patients with VKC refractory to conventional treatment who presented to The Eye Center and The Eye Foundation for Research in Ophthalmology, Riyadh, Saudi Arabia, from June 2011 to December 2014. Refractory to conventional treatment was defined as persistence of symptoms and signs despite the use of conventional treatment prior to presentation. Conventional treatment included topical steroids, cyclosporine, anti-histamines, mast-cell stabilizers, and decongestants. The duration of the disease before presentation was variable. The diagnosis of VKC was based on the clinical findings of symptoms of itching, redness, discharge, and foreign body sensation and signs of conjunctival hyperemia, papillae in the upper palpebral conjunctiva, limbal infiltration, Trantas dots, and superficial punctate keratopathy. Each clinical symptom and sign was assessed and the severity was graded as 0 (normal), $1+$ (mild), $2+$ (moderate), or $3+$ (severe). This is the standard grading system and the documented regime routinely used at our institute. Clinical assessment was carried out before, during, and on the last visit after treatment (average, 9 months). We excluded patients with known hypersensitivity to tacrolimus; patients with infectious eye diseases, including trachoma; pregnant or lactating women; patients on systemic therapy for other atopic diseases; and patients who had recent surgical procedures. Tacrolimus $0.01 \%$ ophthalmic solution was administered to patients twice daily after discontinuation of all previous topical medications. The duration of treatment ranged from 1 month to 29 months (mean, 9 months). The variation in the duration of treatment with topical tacrolimus solution was attributed to the differences in the response to treatment among patients. The treatment was continued during active disease with periodic attempts to withdraw tacrolimus eyedrops whenever possible. On the last follow-up visit, all patients were evaluated for improvement in subjective symptoms, including itching, redness, foreign body sensation, and discharge.

They were also evaluated for improvement in clinical signs, including conjunctival hyperemia, conjunctival papillary hypertrophy, limbal infiltration, Trantas dots, and superficial punctate keratopathy. Improvement in each symptom or sign was defined as control of symptoms and signs without the need for an additional therapy. Ocular surface temperature was measured in selected patients who had serum levels of tacrolimus and $\operatorname{IgE}$.

Tacrolimus eyedrops were compounded by adding balanced salt solution to $1,000 \mu \mathrm{g}$ tacrolimus capsule (Prograf; Astellas Pharma Inc., Tokyo, Japan) to achieve $0.01 \%$ concentration. No preservative was added. The final $\mathrm{pH}$ of the compounded tacrolimus solution was 6 . The compounding of the eyedrops was carried out under sterile condition and laminar flow hood. The patients were asked not to use the tacrolimus eyedrops after 1 month from opening the bottle. They were strictly instructed to keep the bottle clean and to keep it in the refrigerator. Cultures of selected tacrolimus $0.01 \%$ eyedrops were carried out at days 0 and 30 that revealed no growth.

\section{Statistical analysis}

After data collection completion, data analysis was conducted using the SPSS version 19.0 (IBM Corporation, Armonk, NY, USA). Continuous variables were expressed as mean \pm standard deviation (SD). Discrete variables such as symptoms and signs of vernal keratoconjunctivitis were expressed as counts (percentage). Differences before and after treatment were assessed using chi-square test and Fisher's exact test. A $P$-value of $\leq 0.05$ was considered statistically significant.

\section{Results}

There were 62 patients with refractory VKC comprising $49(79 \%)$ male and 13 (21\%) female patients. The median 
age was 12 years (range: 5-47 years). The mean visual acuity at presentation was 20/30 (range: 20/16-20/200). The mean intraocular pressure at presentation was $14 \mathrm{mmHg}$ (range: 7-21 $\mathrm{mmHg}$ ). On presentation, all patients had bilateral VKC that was refractory to conventional topical treatment, including antihistamines, mast-cell stabilizers, decongestants, cyclosporine, and steroids. The main presenting symptoms were itching in $50(81 \%)$ patients, redness in $49(79 \%)$ patients, discharge in $31(50 \%)$ patients, and foreign body sensation in 17 (27\%) patients. Clinical signs included conjunctival hyperemia in 49 (79\%) patients, conjunctival papillary hypertrophy in $34(55 \%)$ patients, Trantas dots in $35(56 \%)$ patients, limbal hypertrophy in $41(66 \%)$ patients, and superficial punctuate keratitis in 17 (27\%) patients.

The median duration of treatment was 7 months (range: 1-29 months). Response to treatment was assessed based on at least 1-grade reduction in severity compared to values before the treatment. Each of the following symptoms of itching, redness, tearing, and foreign body sensation showed statistically significant reduction in severity on the last visit following therapy with tacrolimus eyedrop $(P<0.001$; Table 1). Similarly, each of the clinical signs of conjunctival hyperemia, conjunctival papillary hypertrophy, limbal infiltration, Trantas dots, and superficial punctate keratopathy showed statistically significant reduction in severity $(P<0.001$; Table 2$)$. The improvement in the clinical signs was noted after 2 weeks of initiation of therapy in mild cases and after 4 weeks of initiation of therapy in severe cases. The mean visual acuity on the last visit was 20/25 (range: 20/16-20/120). The mean intraocular pressure on the last visit was $13 \mathrm{mmHg}$ (range: $6-19 \mathrm{mmHg}$ ). The mean conjunctival temperature changed from $35.4^{\circ} \mathrm{C}$ before treatment to $35.1^{\circ} \mathrm{C}$ following treatment. IgE levels were found to be elevated in some patients.

Three $(5 \%)$ out of 62 patients reported mild irritation and/or transient burning sensation at the time of instilling the eyedrop, which subsided during treatment. Three patients developed ocular infection and one patient developed active trachoma after 20 months of therapy. One patient developed

Table I Effect of topical tacrolimus $0.01 \%$ on symptoms of vernal keratoconjunctivitis

\begin{tabular}{lllll}
\hline Symptoms & $\begin{array}{l}\text { N of } \\
\text { affected } \\
\text { patients }\end{array}$ & $\begin{array}{l}\text { Improved } \\
\text { patients, }\end{array}$ & 95\% Cl & P-value \\
\hline Itching & 50 & $4 I(82)$ & $0.73-0.88$ & $<0.000$ I \\
Redness & 49 & $37(75)$ & $0.66-0.83$ & $<0.000$ I \\
Discharge & 3 I & $26(84)$ & $0.73-0.9$ I & $<0.000$ I \\
Foreign body sensation & I7 & I5 (88) & $0.73-0.95$ & $<0.000$ I \\
\hline
\end{tabular}

Abbreviation: $\mathrm{Cl}$, confidence interval.
Table 2 Effect of topical tacrolimus $0.01 \%$ on signs of vernal keratoconjunctivitis

\begin{tabular}{|c|c|c|c|c|}
\hline Signs & $\begin{array}{l}\mathbf{N} \text { of } \\
\text { affected } \\
\text { patients }\end{array}$ & $\begin{array}{l}\text { Improved } \\
\text { patients, } \\
\text { n (\%) }\end{array}$ & $95 \% \mathrm{Cl}$ & $P$-value \\
\hline Conjunctival hyperemia & 49 & $37(75)$ & $0.66-0.83$ & $<0.000$ I \\
\hline $\begin{array}{l}\text { Conjunctival papillary } \\
\text { hypertrophy }\end{array}$ & 34 & $7(2 I)$ & $0.13-0.32$ & $<0.0001$ \\
\hline Limbal hypertrophy & 41 & $35(85)$ & $0.76-0.91$ & $<0.000$ I \\
\hline $\begin{array}{l}\text { Superficial punctate } \\
\text { keratitis }\end{array}$ & 17 & I 5 (88) & $0.73-0.95$ & $<0.0001$ \\
\hline Trantas dots & 35 & $27(77)$ & $0.66-0.85$ & $<0.0001$ \\
\hline
\end{tabular}

Abbreviation: $\mathrm{Cl}$, confidence interval.

mucopurulent conjunctivitis with growth of Staphylococcus epidermidis after 17 months, and one patient developed mucopurulent conjunctivitis with growth of Staphylococcus aureus after 24 months. None of the patients developed cataract, increased intraocular pressure, or infectious keratitis. None of the patients developed malignancy throughout the follow-up period.

\section{Discussion}

Tacrolimus has been widely used for the treatment of atopic disorders such as atopic dermatitis and VKC. Tacrolimus inhibits calcineurin activity, leading to marked suppression of the production of various cytokines by activated T-cells, which are believed to play a major role in the pathogenesis of VKC. ${ }^{5}$ Tacrolimus has also been reported to inhibit calcineurin 100 times more effectively than cyclosporine and was found to be effective in patients whose condition did not respond well to topical cyclosporine therapy. ${ }^{8}$ Eosinophils are major effector cells in ocular inflammation in patients with VKC. Activated eosinophils release cytokines, chemokines, leukotrienes, and epitheliotoxic proteins. These mediators play an important role in eliciting ocular surface inflammation and corneal epithelium damage. ${ }^{1}$ Eosinophils massively infiltrate giant papillae in patients with allergic conjunctivitis. ${ }^{11}$ Tacrolimus reduces eosinophils chemotaxis through inhibition of interleukin 5 production. ${ }^{12}$ Topical tacrolimus was found to be very effective in reducing inflammatory cells, especially eosinophils, as shown in conjunctival cytology studies. ${ }^{13}$

In this retrospective study, we have assessed the safety and efficacy of $0.01 \%$ tacrolimus eyedrop in 62 patients with refractory VKC. There was statistically significant improvement in symptoms and signs of VKC. In addition to conjunctival signs, there was significant improvement in limbal hypertrophy, Trantas dots, and corneal signs such as corneal punctate epithelial erosions. Improvement in corneal 
signs was associated with a change in visual acuity from $20 / 30$ to $20 / 25$ following treatment with topical tacrolimus $0.01 \%$. Among the various clinical signs of our patients, conjunctival papillary hypertrophy was found to have the least response to topical tacrolimus $0.01 \%$. However, previous studies reported improvement in conjunctival papillary reaction. These studies evaluated the efficacy of a higher concentration of topical tacrolimus $(0.1 \%)$ and also included patients with concomitant use of topical steroids. ${ }^{6,8}$

Different forms and concentrations of tacrolimus have been assessed in the treatment of allergic eye diseases, including refractory VKC. The majority of the studies have used $0.1 \%$ concenteration. ${ }^{6-10}$ Some other studies evaluated lower concentrations of tacrolimus, including $0.02 \%$ and $0.03 \% .^{14,15}$ The lowest concentration of topical tacrolimus evaluated for treatment of VKC was $0.005 \%$. The authors found that topical $0.005 \%$ tacrolimus eyedrop seemed to be a safe and effective treatment for steroid-resistant refractory VKC. ${ }^{16}$ However, it was prescribed four times daily. In our study, we used $0.01 \%$ topical tacrolimus twice daily, which may increase compliance. Despite the efficacy of topical tacrolimus, almost all patients reported immediate recurrence of symptoms on discontinuation of therapy.

A common problem with tacrolimus as well as cyclosporine is the possibility to find a nonirritating vehicle for eyedrop preparation. We found that the particles from the tacrolimus capsule are efficiently soluble in water without formation of precipitates. With the use of the solution form, long-term use of $0.01 \%$ tacrolimus was well tolerated. Transient burning sensation at the time of instilling the eyedrop was present in $5 \%$ of our cases and subsided with continued treatment. Intraocular pressure remained normal and the rest of eye examination had no clinical or structural changes. Three of our patients developed infectious conjunctivitis that responded well to antimicrobial therapy. The three patients were on topical tacrolimus for $>1$ year and they developed conjunctivitis during the course of treatment. We believe that this may be an incidental finding. However, treatment with topical tacrolimus modulates the local immune response at the ocular surface and may theoretically increase the risk of infections. ${ }^{7}$ There may be a particular concern about an increased risk of herpes simplex virus keratitis associated with topical tacrolimus. Accordingly, caution is required to prevent possible recurrence during long-term treatment. ${ }^{7,17}$ None of our patients developed herpetic keratitis. Further studies including larger number of patients are needed to find out if there is any increased risk of ocular infection with prolonged therapy with topical tacrolimus.
There may be an increased risk of T-cell lymphoma in atopic dermatitis patients treated with tacrolimus skin ointment. ${ }^{18}$ However, there is no evidence in the literature of an increase in risk of malignancy due to a topical treatment with calcineurin inhibitors. ${ }^{19,20}$ In our study, none of our cases developed malignancy throughout the follow-up period up to 29 months. Even after the application of $0.1 \%$ topical tacrolimus, which is ten times the concentration that we used in our study, the risk of developing malignancy is extremely low. ${ }^{7}$ The maximum blood concentration of tacrolimus following topical use was $<2 \mathrm{ng} / \mathrm{mL}$ in selected cases of our patients. This was less than the high risk level $(10 \mathrm{ng} / \mathrm{mL})$ at which systemic adverse drug reactions might occur. The theoretical risk of adverse effects due to exposure to topical tacrolimus is very low. ${ }^{21}$

Our study, however, suffers from certain limitations. This is a retrospective study with self-evident drawbacks. VKC is a potentially blinding disease with exacerbations and remissions. A prospective, double-masked, clinical trial is needed.

\section{Conclusion}

In conclusion, our study demonstrates the efficacy and safety of $0.01 \%$ tacrolimus solution as a steroid-sparing agent in the management of refractory VKC. Given its high efficacy and safety even after long-term use, tacrolimus may be considered as a first-line treatment for patients with VKC.

\section{Acknowledgments}

This study was supported in part by a fund from The Eye Center and The Eye Foundation for Research in Ophthalmology, Riyadh, Saudi Arabia. The authors would like to thank Doctor Naser Elkum for his help in statistical analysis. Professor Khalid F Tabbara disclosed consulting fee unrelated to the current project from Thea Laboratories (Saudi Arabia). Samir S Shoughy and Mahmoud O Jaroudi do not have any financial interests in this study.

\section{Disclosure}

The authors report no conflicts of interest in this work.

\section{References}

1. Kumar S. Vernal keratoconjunctivitis: a major review. Acta Ophthalmol. 2009;87(2):133-147.

2. Abu El-Asrar AM, Tabbara KF, Geboes K, Missotten L, Desmet V. An immunohistochemical study of topical cyclosporine in vernal keratoconjunctivitis. Am J Ophthalmol. 1996;121:156-161.

3. Bielory L, Frohman LP. Allergic and immunologic disorders of the eye. J Allergy Clin Immunol. 1992;89(1 pt 1):1-15.

4. Ohji M, Kinoshita S, Ohmi E, Kuwayama Y. Marked intraocular pressure response to instillation of corticosteroids in children. Am J Ophthalmol. 1991;112:450-454. 
5. Rallis E, Korfitis C, Gregoriou S, Rigopoulos D. Assigning new roles to topical tacrolimus. Expert Opin Investig Drugs. 2007;16(8): 1267-1276.

6. Ohashi Y, Ebihara N, Fujishima H, et al. A randomized, placebo-controlled clinical trial of tacrolimus ophthalmic suspension $0.1 \%$ in severe allergic conjunctivitis. J Ocul Pharmacol Ther. 2010;26(2): $165-174$.

7. Al-Amri AM. Long-term follow-up of tacrolimus ointment for treatment of atopic keratoconjunctivitis. Am J Ophthalmol. 2014;157(2): 280-286.

8. Fukushima A, Ohashi Y, Ebihara N, et al. Therapeutic effects of $0.1 \%$ tacrolimus eye drops for refractory allergic ocular diseases with proliferative lesion or corneal involvement. Br J Ophthalmol. 2014;98: 1023-1027.

9. Vichyanond P, Tantimongkolsuk C, Dumrongkigchaiporn $\mathrm{P}$, Jirapongsananuruk O, Visitsunthorn N, Kosrirukvongs P. Vernal keratoconjunctivitis: result of a novel therapy with $0.1 \%$ topical ophthalmic FK-506 ointment. J Allergy Clin Immunol. 2004;113(2): 355-358.

10. Zribi H, Descamps V, Hoang-Xuan T, Crickx B, Doan S. Dramatic improvement of atopic keratoconjunctivitis after topical treatment with tacrolimus ointment restricted to the eyelids. J Eur Acad Dermatol Venereol. 2009;23(4):489-490.

11. Takamura E, Uchio E, Ebihara N, et al; Japanese Society of Allergology. Japanese guideline for allergic conjunctival diseases. Allergol Int. 2011; 60:191-203.

12. de Paulis A, Stellato C, Cirillo R, Ciccarelli A, Oriente A, Marone G. Anti-inflammatory effect of FK-506 on human skin mast cells. $J$ Invest Dermatol. 1992;99(6):723-728.
13. Virtanen HM, Reitamo S, Kari M, Kari O. Effect of $0.03 \%$ tacrolimus ointment on conjunctival cytology in patients with severe atopic blepharoconjunctivitis: a retrospective study. Acta Ophthalmol Scand. 2006; 84(5):693-695.

14. Miyazaki D, Tominaga T, Kakimaru-Hasegawa A, Nagata Y, Hasegawa J, Inoue Y. Therapeutic effects of tacrolimus ointment for refractory ocular surface inflammatory diseases. Ophthalmology. 2008;115(6): 988-992.

15. Kymionis GD, Goldman D, Ide T, Yoo SH. Tacrolimus ointment $0.03 \%$ in the eye for treatment of giant papillary conjunctivitis. Cornea. 2008; 27(2):228-229.

16. Kheirkhah A, Zavareh MK, Farzbod F, Mahbod M, Behrouz MJ. Topical $0.005 \%$ tacrolimus eye drop for refractory vernal keratoconjunctivitis. Eye. 2011;25(7):872-880.

17. Joseph MA, Kaufman HE, Insler M. Topical tacrolimus ointment for treatment of refractory anterior segment inflammatory disorders Cornea. 2005;4:417-420.

18. Rita L, William L, James C, Schottinger J, Yoshinaga M, Millares M. Association between exposure to topical tacrolimus or pimecrolimus and cancers. Ann Pharmacother. 2009;43:1956-1963.

19. Thaçi D, Salgo R. Malignancy concerns of topical calcineurin inhibitors for atopic dermatitis: facts and controversies. Clin Dermatol. 2010; 28(1):52-56.

20. Tennis P, Gelfand JM, Rothman KJ. Evaluation of cancer risk related to atopic dermatitis and use of topical calcineurin inhibitors. $\mathrm{Br} J$ Dermatol. 2011;165(3):465-473.

21. Ebihara N, Ohashi Y, Fujishima H, et al. Blood level of tacrolimus in patients with severe allergic conjunctivitis treated by $0.1 \%$ tacrolimus ophthalmic suspension. Allergol Int. 2012;61(2):275-282.
Clinical Ophthalmology

\section{Publish your work in this journal}

Clinical Ophthalmology is an international, peer-reviewed journal covering all subspecialties within ophthalmology. Key topics include: Optometry; Visual science; Pharmacology and drug therapy in eye diseases; Basic Sciences; Primary and Secondary eye care; Patient Safety and Quality of Care Improvements. This journal is indexed on

\section{Dovepress}

PubMed Central and CAS, and is the official journal of The Society of Clinical Ophthalmology (SCO). The manuscript management system is completely online and includes a very quick and fair peer-review system, which is all easy to use. Visit http://www.dovepress.com/ testimonials.php to read real quotes from published authors. 